\title{
Effect of silencing SATB1 on proliferation, invasion and apoptosis of A549 human lung adenocarcinoma cells
}

\author{
BO HUANG ${ }^{1}$, HONGLI ZHOU ${ }^{2}$, SIWANG WANG ${ }^{1}$, XIAN PING LANG ${ }^{1}$ and XIAODONG WANG ${ }^{1}$ \\ Departments of ${ }^{1}$ Thoracic Surgery and ${ }^{2}$ Kidney Diseases, The First Affiliated Hospital of Liaoning Medical University, \\ Jinzhou, Liaoning 121000, P.R. China
}

Received May 18, 2015; Accepted July 5, 2016

DOI: $10.3892 / \mathrm{ol} .2016 .5179$

\begin{abstract}
The present study aimed to explore the clinical characteristics of special adenine-thymine-rich sequence-binding protein 1 (SATB1) in lung adenocarcinoma and its role in the proliferation, invasion, migration and apoptosis of the lung adenocarcinoma cell line A549. The expression of SATB1 was first studied in tumor tissues of lung adenocarcinoma and adjacent non-tumor tissues. The siRNA green fluorescent protein expression vector of SATB1 was constructed and transfected into the lung adenocarcinoma cell line A549, then a fluorescence microscope was used to study the transfection efficiency. Western blot analysis was adopted to measure the silencing efficiency. 3-(4,5-dimethylthiazol-2-yl)-2,5-diphenyltetrazolium bromide (MTT), Transwell and scratch assays were used to study cell proliferation, invasion and migration activity, and the apoptosis rate was tested by flow cytometry. SATB1 expression was low in the adjacent non-tumor tissues but high in lung adenocarcinoma tissues, and it was reversely proportional to the differentiation degree. Following transfection with SATB1-siRNA, the expression of SATB1 in A549 cells was blocked $(\mathrm{P}<0.01)$. In addition, the proliferation, invasion and migration abilities of cells decreased significantly while the apoptosis rate increased significantly $(\mathrm{P}<0.01)$. In conclusion SATB1 is closely associated with the pathogenesis and development of lung adenocarcinoma.
\end{abstract}

\section{Introduction}

Lung adenocarcinoma is a type of non-small cell lung cancer. It is frequently observed in females and smokers. Lung adenocarcinoma usually originates in the bronchial epithelium, with certain cases originating from the large bronchial mucous

Correspondence to: Professor Xiaodong Wang, Department of Thoracic Surgery, The First Affiliated Hospital of Liaoning Medical University, 2 People Street, Jinzhou, Liaoning 121000, P.R. China

E-mail: hong33lizhou@163.com

Key words: lung cancer, siRNA, special adenine-thymine-rich sequence-binding protein 1 glands. Its growth is generally slow, but occasionally hematogenous metastasis occurs in the early phase. Lymph node metastasis occurs late in the disease (1). To date, although the histopathological progression of lung adenocarcinoma has been thoroughly described, the molecular underpinnings are less well understood (2).

Special adenine-thymine-rich sequence-binding protein 1 (SATB1) is a nuclear matrix attachment region binding protein which is located in the short arm of chromosome 3 and includes 763 amino acids (3). SATB1 is involved in the development of thymocytes, maturation of $\mathrm{T}$ cells and the formation of chromosome structure. Loss of SATB1 has been demonstrated to lead to a change of at least $2 \%$ of genes in mice (4). A study by Han et al revealed that SATB1 plays a key role in the development of breast carcinoma (5). A subsequent study demonstrated strong expression of SATB1 in various tumor cells (6-9). There have been no studies of the SATB1 gene in lung adenocarcinoma. In the present study, the lung adenocarcinoma cell line A549 was cultured in vitro, and SATB1 siRNA was constructed and transfected into A549 cells to silence the SATB1 gene. The changes in cell proliferation, invasion, migration and apoptosis were observed.

\section{Materials and methods}

Ethics. The present study was approved and registered by the ethics committee of the First Affiliated Hospital of Liaoning Medical University, China, in January 2012. The related screening and analysis of the resected samples was approved by the ethics committee of Liaoning Medical University, and written consent forms for the use of these samples were signed and participation in the study was agreed upon by all subjects.

Sample collection. A total of 60 lung adenocarcinoma and 16 adjacent normal tissue samples (at least $5 \mathrm{~cm}$ away from the edge of the cancer tissue) were collected from the sample preservation center at the First Affiliated Hospital of Liaoning Medical University. These samples were all resected in the Department of Thoracic Surgery between January 2012 and December 2013. The inclusion criteria of the samples were: i) Patients had not received any prior radiotherapy or chemotherapy treatment; ii) each patient had received a medical examination including cranial computed tomography 
(CT) scan, chest CT scan, abdominal CT scan and emission computed tomography, from which the tumor-node-metastasis (TNM) stage of the patient could be clearly defined; iii) patients had received radical surgery with sufficient tissue samples prepared in paraffin blocks for further testing; iv) patients who had at least two concurrent primary tumors were excluded. All samples were fixed in $10 \%$ formaldehyde and paraffin-embedded. The samples were routinely and serially sectioned at a thickness of $5 \mu \mathrm{m}$, and then immunohistochemically stained. The lung adenocarcinoma cases were staged according to the TNM staging system stipulated in the seventh edition of the American Joint Committee on Cancer (AJCC) Cancer Staging Manual (2009) (10).

Immunohistochemistry. Sections were deparaffinized and hydrated in a stepwise xylene and graded ethanol, washed with phosphate-buffered saline (PBS), and recovered through microwave irradiation. A $3 \% \mathrm{H}_{2} \mathrm{O}_{2}$ solution was added and cultured for $10 \mathrm{~min}$, and then washed with PBS. Goat blocking serum was supplied and cultured under room temperature and the diluted primary antibodies were applied (1:100). After storing overnight at $4^{\circ} \mathrm{C}$, the sections were washed in PBS, then secondary antibodies were added and the sections were cultured at $37^{\circ} \mathrm{C}$ for $20 \mathrm{~min}$. Freshly prepared 3,3'-diaminobenzidine chromogenic reagent was applied, and the sections were cultured at $37^{\circ} \mathrm{C}$ for 5 to $10 \mathrm{~min}$. Nuclei were then stained with hematoxylin and eosin (HE).

Cell lines and culture conditions. The human lung adenocarcinoma cell line A549 was obtained from Shanghai Biological Sciences Institute in China. Cells were cultured in RPMI-1640 supplemented with $10 \%$ fetal bovine serum (FBS), $10 \mathrm{U} / 1$ penicillin $\mathrm{G}$ and $100 \mathrm{mg} / 1$ streptomycin at $37^{\circ} \mathrm{C}$ in a humidified atmosphere containing $5 \% \mathrm{CO}_{2}$.

Preparation of target vector and transfection. Based on the SATB1 cDNA sequence in Gene Bank, three pairs of synthesized oligonucleotide were designed (Dalian Biotechnologies, Dalian, China). The sequences used were as follows: (Si-1) F: 5'-GATCCCCGGATTTGGAAGAGAGTGTCTTCAAGA GAGACACTCTCTTCCAAATCCTTTTTGGAAA-3'; (Si-1) R: 5'-AGCTTTTCCAAAAAGGATTTGGAAGAGAGTGTC TCTCTTGAAGACACTCTCTTCCAAATCCGGG-3'; (Si-2) F: 5'-GATCCCCGTCCACCTTGTCTTCTCTCTTCAAGA GAGAGAGAAGACAAGGTGGACTTTTTGGAAA-3'; (Si-2) R: 5'-AGCTTTTCCAAAAAGCCACCTTGTCTTCTC TCTCTCTTGAAGAGAGAAGACAAGGTGGACGGG-3'; (Si-N) (control group) F: 5'-GATCCGCGAGACCTCAGT ATGTTACCTGTGAAGCCACAGATGGGGTAACATACT GAGGTCTCGCTTTTTTG-3'. Oligonucleotide was annealed and ligated with pRNAT-U6.1/Neo-siRNA using T4 DNA ligase. The three constructed recombinant plasmids SATB1-siRNA-1, SATB1-siRNA-2 and SATB1-siRNA-N were verified by sequencing and restriction endonuclease digestion. The A549 cells were seeded ( $2 \times 10^{5}$ cells/well) in six-well plates. Following incubation for $24 \mathrm{~h}$, the cells were transfected with SATB1-siRNA-1, SATB1-siRNA-2 and SATB1-siRNA-N plasmid in serum-free medium using Lipofectamine 2000 reagent (Invitrogen, Carlsbad, CA, USA) according to the manufacturer's instructions.
Western blot analysis of SATB1. Forty-eight hours after transfection, cells were washed three times with ice-cold PBS, and then centrifuged at $4^{\circ} \mathrm{C}$ for $30 \mathrm{~min}(13,000 \mathrm{x} \mathrm{g})$. The supernatant was collected and the bicinchoninic acid method was used to determine the protein concentration. A $10 \%$ polyacrylamide gel was prepared to load protein samples, and 5\% nonfat dry milk was added to block the non-specific antigen. The primary antibody (1:250; rabbit anti-human SATB1 polyclonal antibody) and the secondary antibody (1:500; goat anti-rabbit antibody) were applied. Each sample was also probed with $\beta$-actin antibody as a loading control.

MTT assay. Twenty-four hours after transfection, cells from the four groups were loaded on a 96 -well plate at $1 \times 10^{3}$ cells/well and cultured with RPMI-1640 medium with $10 \%$ FBS, at time points of 24, 48 and $72 \mathrm{~h}$. The medium was removed from each well, and $20 \mu 1$ 3-(4,5-dimethylthiazol-2-yl)-2,5-diphenyltetrazolium bromide (MTT; $5 \mathrm{mg} / \mathrm{ml}$ in PBS) was added in the absence of light. Formazan crystals were produced over a 4-h incubation period. Then the supernatant was removed, and $150 \mu \mathrm{l}$ dimethyl sulfoxide was added to each well. The dark blue MTT crystals were dissolved by agitating the plates at room temperature for $10 \mathrm{~min}$, and the absorbance was then measured on a Bio-Rad microplate reader (Bio-Rad, Hercules, CA, USA) using a test wavelength of $490 \mathrm{~nm}$ and a reference wavelength of $570 \mathrm{~nm}$.

Transwell assay. The invasion of A549 cells was assayed using modified Transwell chambers. The polycarbonate filter (pore size, $8 \mu \mathrm{m}$ ) which separates the upper and lower compartments of the chamber was coated with $50 \mu \mathrm{g}$ reconstituted basement membrane (Matrigel, BD Biosciences, Bedford, MA, USA). Thirty-six hours after transfection, the full medium was replaced with serum-free culture medium. Eight hours later, it was digested to a suspension at a density of $1 \times 10^{4} / \mathrm{ml}$. Cells were seeded into the Transwell chamber. The chamber was placed into a 24-well culture plate with $500 \mu$ l RPMI-1640 medium containing $15 \%$ serum added outside of the chamber, and $200 \mu \mathrm{l}$ cell suspension was added to the chamber. After $48 \mathrm{~h}$ of incubation at $37^{\circ} \mathrm{C}$, cells on the upper surface of the filter that had not invaded through the Matrigel were removed completely with cotton swabs. Cells that had invaded remained on the filter. Cells on the polycarbonate filter were fixed with HE. The number of invasive cells was counted under a microscope (magnification, $\mathrm{x} 200$ ).

Scratch assay. The migration ability of A549 cells was performed in a 24-well culture plate. Following transfection, a horizontal wound (scratch) was made on the cells with a tiny spear. Cell migration was observed at 24, 48 and $72 \mathrm{~h}$ after transfection, and the scratch spaces were analyzed.

Flow cytometry. Forty-eight hours after transfection, the cells were washed with PBS twice, and then digested and centrifuged. Then apoptosis detection was processed according to the instructions of the kit (BD Pharmingen ${ }^{\mathrm{TM}}$ Annexin V-PE Apoptosis Detection Kit I; BD Biosciences): Cells were resuspended with $1 \mathrm{X}$ binding buffer $\left(1 \times 10^{6} / \mathrm{ml}\right)$. A total of $100 \mu \mathrm{l}$ was drawn, and $5 \mu \mathrm{l}$ PE Annexin V and $5 \mu 1$ 7-AAD were added. Cells were cultured in a rotary system at room 
Table I. Correlation between positive expression of SATB1 protein in lung adenocarcinoma tissues and patient characteristics.

\begin{tabular}{|c|c|c|c|c|c|c|}
\hline \multirow[b]{2}{*}{ Characteristic } & \multirow[b]{2}{*}{$\mathrm{n}(60)$} & \multicolumn{3}{|c|}{ SATB1 } & \multirow[b]{2}{*}{$\chi^{2}$} & \multirow[b]{2}{*}{ P-value } \\
\hline & & - & + & ++ & & \\
\hline \multicolumn{7}{|l|}{ Gender } \\
\hline Male & 27 & 10 & 5 & 12 & \multirow[t]{2}{*}{2.184} & \multirow[t]{2}{*}{0.336} \\
\hline Female & 33 & 14 & 10 & 9 & & \\
\hline \multicolumn{7}{|l|}{ Age } \\
\hline$\leq 60$ & 24 & 10 & 6 & 8 & \multirow[t]{2}{*}{0.060} & \multirow[t]{2}{*}{0.971} \\
\hline$>60$ & 36 & 14 & 9 & 13 & & \\
\hline \multicolumn{7}{|c|}{ Degree of differentiation } \\
\hline Well & 20 & 14 & 3 & 3 & & \\
\hline Moderate & 23 & 7 & 7 & 9 & & \\
\hline Poor & 17 & 3 & 5 & 9 & 12.315 & 0.015 \\
\hline \multicolumn{7}{|l|}{ TNM stage } \\
\hline Stages I and II & 44 & 20 & 13 & 11 & & \\
\hline Stage III & 16 & 4 & 2 & 10 & 7.305 & 0.026 \\
\hline
\end{tabular}

SATB1, special adenine-thymine-rich sequence-binding protein 1; TNM, tumor-node-metastasis.
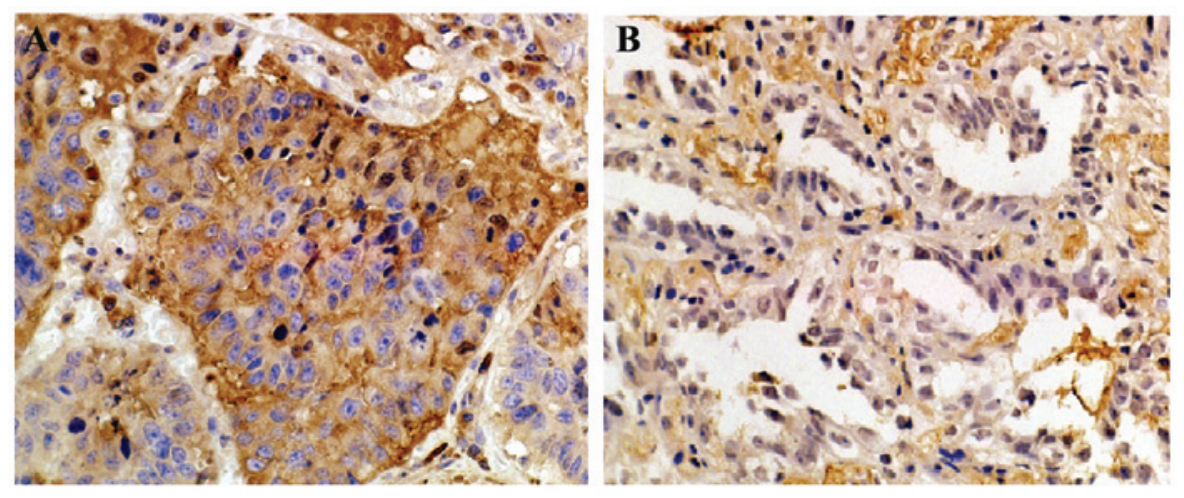

Figure 1. Immunohistochemistry of special adenine-thymine-rich sequence-binding protein 1 in lung adenocarcinoma tissues. (A) Poorly differentiated tissue, (B) well-differentiated tissue.

temperature for $15 \mathrm{~min}$, then $400 \mu 11 \mathrm{X}$ binding buffer was added, and the cells were analyzed within one hour.

Statistical analysis. The images were analyzed by Quantity One software (Bio-Rad, Berkeley,CA, USA). All laboratory data are presented as the means \pm standard deviation. The $\chi^{2}$ test and single factor analysis of variance were performed with SPSS 17.0 software (SPSS, Inc., Chicago, IL, USA). $\mathrm{P}<0.05$ was considered to indicate a statistically significant difference.

\section{Results}

Patient characteristics. A total of 60 samples were selected successfully, 27 of which were resected from males and 33 from females, with an average age of 54 years (range, 37 to 75). Among the samples, 20 cases were well differentiated, 23 cases were moderately differentiated, and 17 cases were poorly differentiated. Forty-four cases were stage I or II, and 16 cases were stage III (Table I).
SATB1 expression in lung adenocarcinoma tissues and adjacent normal tissues. Immunohistochemistry revealed that SATB1 protein was mainly expressed in the cytoplasm and the nuclei, and exhibited yellow or brown colored staining. Its expression was significantly higher in the poorly differentiated cells when compared with the well-differentiated cells. The expression of SATB1 in the lung adenocarcinoma tissues was not correlated with patient age or gender (Table I). A statistical difference was noted in SATB1 protein levels among the lung adenocarcinoma tissues with different degrees of differentiation $\left(\chi^{2}=12.315, \mathrm{P}<0.001\right)$, which were negatively correlated with the expression of SATB1 (Fig. 1). A statistical difference was observed in the expression of SATB1 among the TNM stages in the lung adenocarcinoma cases $\left(\chi^{2}=7.305, \mathrm{P}=0.026\right)$, and the expression was positively correlated with TNM stage. There were $60 \%(36 / 60)$ of cases with positive expression of SATB1 protein among the lung adenocarcinoma tissues while the rate of positive expression was significantly low in the adjacent normal tissues $(18.75 \%, 3 / 16, \mathrm{P}<0.001$, Table II). 
Table II. Correlation between positive expression of SATB1 protein in lung adenocarcinoma tissues and adjacent normal lung tissues.

\begin{tabular}{llrrrrr}
\hline & & & \multicolumn{2}{c}{ SATB1 } & & \\
\cline { 6 - 6 } Tissue & $\mathrm{n}$ & - & + & ++ & $\chi^{2}$ & P-value \\
\hline Tumor tissues & 60 & 24 & 15 & 21 & & \\
Adjacent normal & 16 & 13 & 2 & 1 & 8.904 & 0.012 \\
\hline
\end{tabular}

SATB1, special adenine-thymine-rich sequence-binding protein 1.
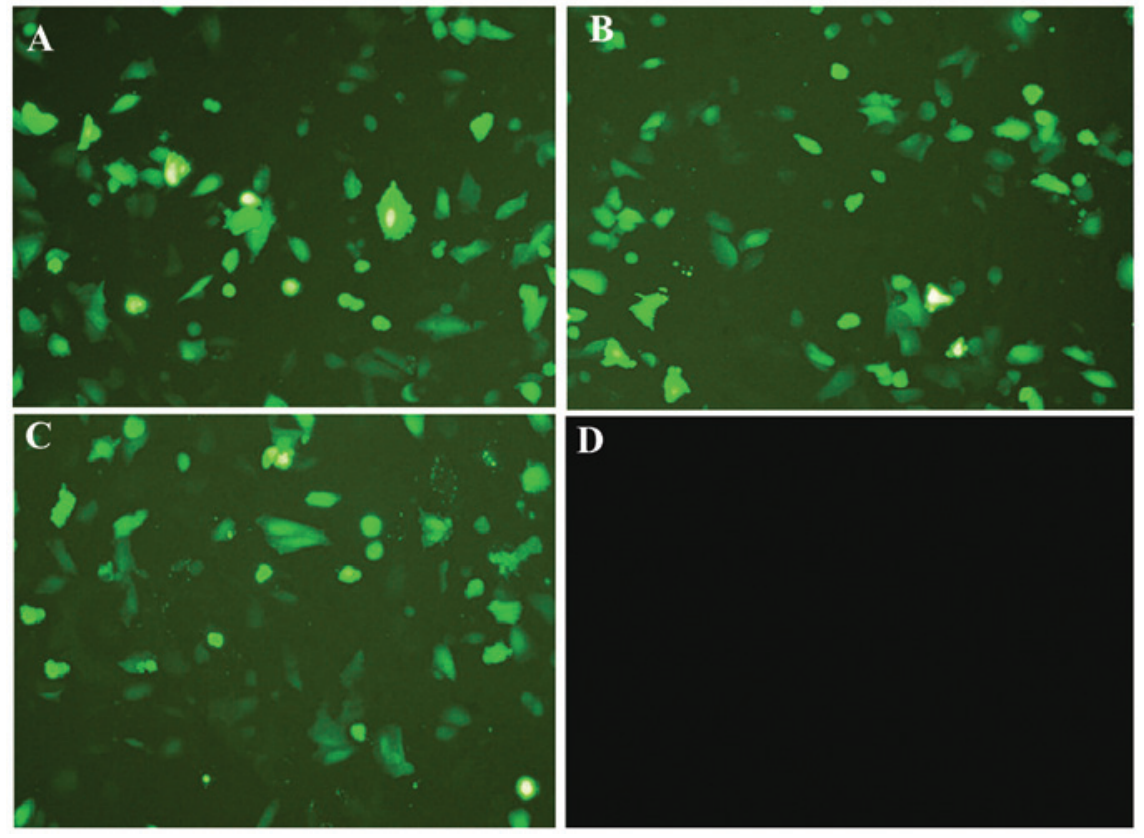

Figure 2. Green fluorescent protein expression of A549 cells $48 \mathrm{~h}$ after transfection. (A) SATB1-siRNA-1 group; (B) SATB1-siRNA-2 group; (C) SATB1-siRNA-N group; (D) Blank group. Magnification, x100. SATB1, special adenine-thymine-rich sequence-binding protein 1.
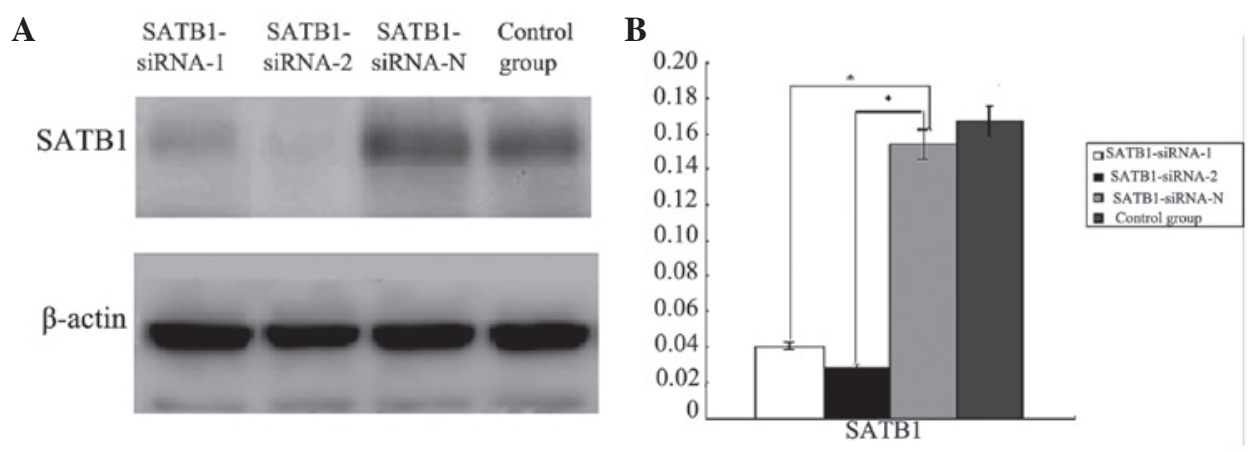

Figure 3. Expression levels of special adenine-thymine-rich sequence-binding protein 1 (SATB1) are decreased following transfection. (A) Western blot analysis results. $\beta$-actin served as the control. (B) Quantification of expression as a histogram. ${ }^{\text {"P }}<0.01$ compared with blank control.

Fluorescence microscopy. After the A549 cells were transfected with SATB1-siRNA-1, SATB1-siRNA-2 or SATB1-siRNA-N, green fluorescence was observed in the cytoplasm. As shown in Fig. 2, under fluorescence microscopy, the transfection efficiency of the three groups (SATB1-siRNA-1, SATB1-siRNA-2 and SATB1-siRNA-N) was satisfactory with all exceeding $75 \%$. It was observed that certain cells treated with SATB1-siRNA were less confluent or became smaller and orbicular compared with the control. Consistently, there were fewer cells in the SATB1-siRNA-1 and SATB1-siRNA-2 transfected cells compared with the SATB1-siRNA-N transfected and control cells cultured for $72 \mathrm{~h}$ after transfection. The SATB1-siRNA treatment decreased the number of A549 cells, implying that SATB1 is involved in cell cycle progression and cell survival. 


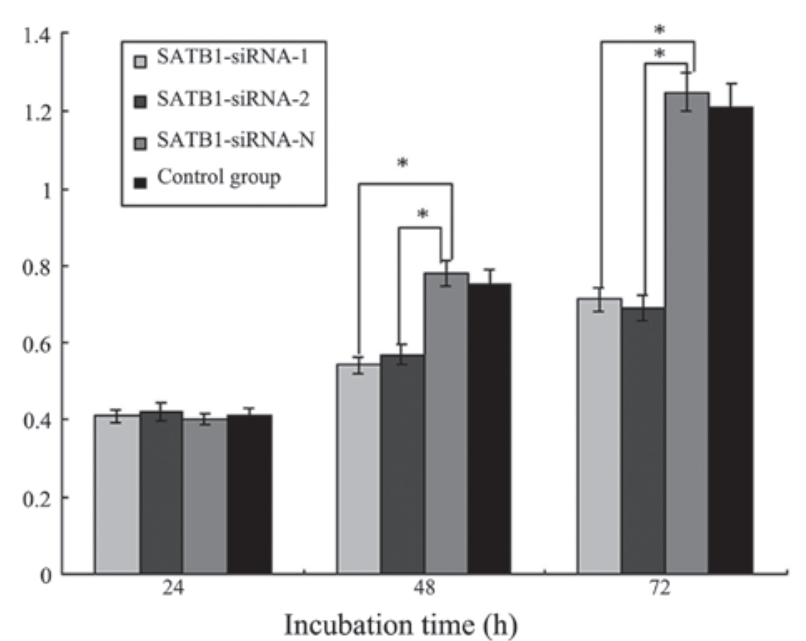

Figure 4. Proliferation ability decreased following transfection. Proliferation was tested by 3-(4,5-dimethylthiazol-2-yl)-2,5-diphenyltetrazolium bromide (MTT) assay. A decrease in the proliferation potential of cells transfected with SATB1-siRNA was noted. Lung adenocarcinoma cells seeded in 96-well microplates were cultured for 24, 48 and $72 \mathrm{~h}$, and the cell number was determined by absorbance as described in Materials and methods. ${ }^{*} \mathrm{P}<0.05$ compared with SATB1-siRNA-N (analysis of variance). Data are representative of 1 of 5 of independent assays. SATB1, special adenine-thymine-rich sequence-binding protein 1 .

Western blot analysis of SATB1. In order to assess whether SATB1-siRNA effectively silenced SATB1 expression in A549 cells, protein was extracted from the A549 cells. Cell lysates were analyzed for SATB1 protein expression using western blot analysis with SATB1 antibodies. As shown in Fig. 3, following transfection with SATB1-siRNA-1 and SATB1-siRNA-2, a significant decrease in SATB1 protein expression was observed. SATB1 protein levels were noted to be significantly downregulated following transfection with SATB1-siRNA-1 and SATB1-siRNA-2 compared with the untransfected cells or those transfected with SATB1-siRNA-N.

Cell proliferation assay. A549 cell proliferation was analyzed using the MTT assay. As shown in Fig. 4, compared with the A549 cells transfected with SATB1-siRNA-N, the proliferation of the A549 cells transfected with SATB1-siRNA-1 and SATB1-siRNA-2 was significantly reduced to $72.50 \%$ and $70.00 \%(\mathrm{P}<0.05), 65.85 \%$ and $69.51 \%(\mathrm{P}<0.05)$, and $58.68 \%$ and $57.02 \%(\mathrm{P}<0.01)$ at 24,48 and $72 \mathrm{~h}$, respectively. No significant difference was observed between the untransfected A549 cells and those transfected with SATB1-siRNA-N $(\mathrm{P}>0.05)$.

Cell invasion and migration assay. To investigate the role of SATB1-siRNA in lung adenocarcinoma cell invasion, Transwell invasion assays were performed. Untransfected A549 cells and cells transfected with SATB1-siRNA-1, SATB1-siRNA-2 and SATB1-siRNA-N were incubated for $48 \mathrm{~h}$ on Matrigel-coated filters which were then stained with $\mathrm{HE}$ and analyzed using a microscope. The number of A549 cells transfected with SATB1-siRNA-1 and SATB1-siRNA-2 observed on the filter significantly decreased compared with the number of untransfected and SATB1-siRNA-N transfected cells $(\mathrm{P}<0.05)$. Furthermore, no significant difference in cell number was observed between the SATB1-siRNA-N group and the control

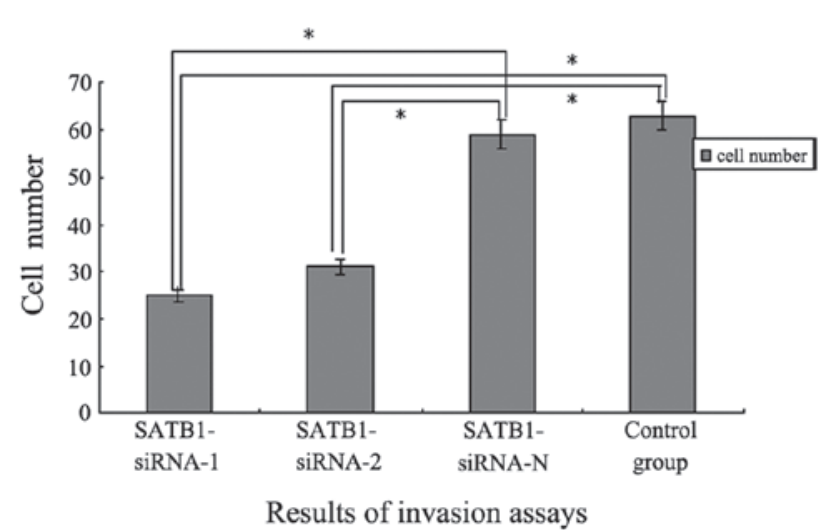

Figure 5. Migration ability decreased following transfection. Histogram of the transmembrane cell count comparison. A reduced number of SATB1-siRNA-1 and SATB1-siRNA-2 transfected cells was noted compared with the number of untransfected or SATB1-siRNA-N trasfected cells. ${ }^{*} \mathrm{P}<0.05$ compared with A549 cells and SATB1-siRNA-N (analysis of variance). Data are representative of 1 of 5 of independent assays. SATB1, special adenine-thymine-rich sequence-binding protein 1 .

group ( $\mathrm{P}>0.05$; Fig. 5). These data suggested that silencing SATB1 using transient transfection with SATB1-siRNA may inhibit lung adenocarcinoma cell invasion in vitro.

The migration ability test of transfected cells was performed $72 \mathrm{~h}$ after transfection. The transmembrane cell number in the SATB1-siRNA-1 and SATB1-siRNA-2 groups was only half of the number in the SATB1-siRNA-N and blank control groups. This indicated that the migration ability was inhibited significantly in the SATB1-siRNA-1 and SATB1-siRNA-2 groups. The scratch width measure results supported the results of the above-mentioned test: the reducing space in SATB1-siRNA-1 and SATB1-siRNA-2 from 0 to $72 \mathrm{~h}$ following transfection was far below that measured from the SATB1-siRNA-N and blank control groups (data shown in Table III).

Apoptosis rate increases following transfection. Flow cytometric analysis revealed that the apoptosis rate significantly increased $(\mathrm{P}<0.01)$ in the SATB1-siRNA-1 and SATB1-siRNA-2 transfected cells compared with the SATB1-siRNA-N transfected cells; there was no significant difference in the apoptotic rate between cells transfected with SATB1-siRNA-N and the blank control ( $P>0.05$; Table IV).

\section{Discussion}

Lung adenocarcinoma, in which hematogenous metastasis usually occurs in the early stage, is a type of non-small-cell lung cancer. Although radiotherapy and chemotherapy have produced modest benefits in certain patients, they have a tendency to relapse and become resistant to numerous drugs following traditional therapies (11). Therefore early detection and providing a reliable therapeutic target are crucial. The identification of siRNAs may well be one of the transforming events in biology in the past decade (12). This technology has become an essential tool in the studies of gene function, carcinoma and viral disease therapy $(13,14)$. In the present study, siRNAs targeting SATB1-SATB1-siRNA-1 and SATB1-siRNA-2 were constructed successfully. Our results revealed that transfection with SATB1-siRNA-1 or SATB1-siRNA-2 into the lung 
Table III. Width of scratch in each time period for each group of cells (mean \pm standard deviation, $n=5$ ).

\begin{tabular}{lccrr}
\hline Time & SATB1-siRNA-1 & SATB1-siRNA-2 & SATB1-siRNA-N & Blank control \\
\hline $0 \mathrm{~h}(\mathrm{~mm})$ & $34.56 \pm 1.29$ & $33.06 \pm 2.31$ & $34.26 \pm 1.36$ & $34.76 \pm 1.85$ \\
$24 \mathrm{~h}(\mathrm{~mm})$ & $27.77 \pm 2.17$ & $26.48 \pm 1.68$ & $26.12 \pm 1.16$ & $25.79 \pm 1.11$ \\
$48 \mathrm{~h}(\mathrm{~mm})$ & $23.61 \pm 1.25^{\mathrm{a}}$ & $23.61 \pm 2.30^{\mathrm{a}}$ & $14.95 \pm 1.13$ & $13.85 \pm 1.69$ \\
$72 \mathrm{~h}(\mathrm{~mm})$ & $16.35 \pm 1.56^{\mathrm{a}}$ & $17.89 \pm 1.95^{\mathrm{a}}$ & $7.82 \pm 1.23$ & $6.59 \pm 2.36$
\end{tabular}

${ }^{\mathrm{a}} \mathrm{P}<0.01$ compared with SATB1-siRNA-N group. SATB1, special adenine-thymine-rich sequence-binding protein 1.

Table IV. Analysis of rate of apoptosis for each cell group.

\begin{tabular}{lc}
\hline Group & Apoptosis rate $(\%)$ \\
\hline SATB1-siRNA-1 & $21.36 \pm 1.19^{\mathrm{a}}$ \\
SATB1-siRNA-2 & $20.45 \pm 1.85^{\mathrm{a}}$ \\
SATB1-siRNA-N & $6.12 \pm 1.36$ \\
Blank control & $5.35 \pm 1.65$ \\
\hline
\end{tabular}

${ }^{\text {aP }}<0.01$ compared with SATB1-siRNA-N group. SATB1, special adenine-thymine-rich sequence-binding protein 1.

adenocarcinoma cell line A549 could inhibit cell proliferation and invasion significantly. In addition, SATB1-siRNA could induce the apoptosis of lung adenocarcinoma cells in vitro.

SATB1, which was originally characterized as a regulator in T cell differentiation, was noted to be overexpressed in metastatic breast cancer cell lines and in human tissue specimens from the advanced stages of breast carcinoma with metastasis (15). There are few studies reporting on the expression of SATB1 in lung cancers, but the role of SATB1 is controversial: a study in squamous cell lung cancer and non-small-cell lung cancers revealed that SATB1 expression was lost, and the loss of SATB1 predicted poor prognosis in squamous cell carcinomas (16). Furthermore, Huang et al demonstrated that the expression of SATB1 was much higher in SCLC tissues with or without metastasis than in normal lung tissues (17).

In the present study, we noted that SATB1 was highly expressed in lung adenocarcinoma tissues compared with adjacent normal tissue. Significantly, the expression of SATB1 was observed to be closely correlated with the cancer cell differentiation degree and TNM stage, which suggested that SATB1 might contribute to invasion and metastasis in lung adenocarcinoma. Based on this, we constructed SATB1-siRNA and silenced SATB1 in A549 cells. Our results revealed that SATB1-siRNA could induce lung adenocarcinoma cell apoptosis following transfection of SATB1-siRNA into lung adenocarcinoma cells. Metastasis is the final step in solid tumor progression and the most common cause of mortality in cancer patients. Controlling the proliferation, invasion and migration is likely to improve the survival rate of cancer patients (18). A previous study demonstrated that SATB1 plays an significant role in the process of proliferation, invasion and migration (19). Consistent with that previous study, the present results also revealed that the proliferation, invasion and migration ability of lung adenocarcinoma cells declined notably following transfection with SATB1-siRNA. These results suggest that SATB1 may be an ideal target for the treatment of lung adenocarcinoma. As for the mechanisms of SATB1 influencing proliferation, invasion and migration in lung adenocarcinoma cells, there has been little research to date. However, numerous studies into the roles of SATB1 in breast and other cancers have been conducted. Cai et al observed that SATB1 could induce a change in the expression of more than 1000 genes (20). Some of these genes are associated with cancer invasion and metastasis, including MMP2, MMP9 and CTGF $(19,21)$. We intend to further study the detailed mechanisms in lung adenocarcinoma cells.

In summary, our study revealed that SATB1 was highly expressed in lung adenocarcinoma tissues compared with adjacent normal tissues. The expression of SATB1 was closely correlated with cancer cell differentiation and TNM stage. The transfection vector system we constructed significantly downregulated the SATB1 level in lung adenocarcinoma cells and it also inhibited cell proliferation, invasion and migration, and induced cell apoptosis. SATB1 could regulate the invasion and migration of lung adenocarcinoma cells, which may provide essential clues for more effective targeting of lung adenocarcinoma and other cancers with aberrant SATB1 activation.

\section{Acknowledgements}

This study was supported by the Education Department of Liaoning Province (series number L2012300) and the Science and Technology Department of Liaoning Province (series number 2013022038 and 2013022046).

\section{References}

1. Yatabe Y, Borczuk AC and Powell CA: Do all lung adenocarcinomas follow a stepwise progression? Lung Cancer 74: 7-11, 2011.

2. Kadara H, Kabbout M and Wistuba II: Pulmonary adenocarcinoma: a renewed entity in 2011. Respirology 17: 50-65, 2012.

3. Xu L, Deng HX, Xia JH, Yang Y, Fan CH, Hung WY and Siddque T: Assignment of SATB1 to human chromosome band 3p23 by in situ hybridization. Cytogenet Cell Genet 77: 205-206, 1997.

4. Beyer M, Thabet Y, Müller RU, Sadlon T, Classen S, Lahl K, Basu S, Zhou X, Bailey-Bucktrout SL, Krebs W, et al: Repression of the genome organizer SATB1 in regulatory T cells is required for suppressive function and inhibition of effector differentiation. Nat Immunol 12: 898-907, 2011.

5. Han HJ, Russo J, Kohwi Y and Kohwi-Shigematsu T: SATB1 reprogrammes gene expression to promote breast tumour growth and metastasis. Nature 452: 187-193, 2008. 
6. Zhang Y, Tian X, Ji H, Guan X, Xu W, Dong B, Zhao M, Wei M, Ye C, Sun Y, et al: Expression of SATB1 promotes the growth and metastasis of colorectal cancer. PLoS One 9: e100413, 2014.

7. Han B, Luan L, Xu Z and Wu B: Expression and biological roles of SATB1 in human bladder cancer. Tumour Biol 34: 2943-2949, 2013.

8. Shukla S, Sharma H, Abbas A, MacLennan GT, Fu P, Danielpour D and Gupta S: Upregulation of SATB1 is associated with prostate cancer aggressiveness and disease progression. PLoS One 8: e53527, 2013

9. Zuk K, Peczek L, Stec-Michalska K, Medrek M and Nawrot B SATB1 expression in gastric mucosa in relation to Helicobacter pylori infection and family history of gastric cancer. Adv Med Sci 57: 237-243, 2012.

10. Groome PA, Bolejack V, Crowley JJ, Kennedy C, Krasnik M, Sobin LH and Goldstraw P; IASLC International Staging Committee; Cancer Research and Biostatistics; Observers to the Committee; Participating Institutions: The IASLC Lung Cancer Staging Project: Validation of the proposals for revision of the $\mathrm{T}, \mathrm{N}$, and $\mathrm{M}$ descriptors and consequent stage groupings in the forthcoming (seventh) edition of the TNM classification of malignant tumours. J Thorac Oncol 2: 694-705, 2007.

11. Notsuda H, Sakurada A, Endo C, Okada Y, Horii A, Shima H and Kondo T: p190A RhoGAP is involved in EGFR pathways and promotes proliferation, invasion and migration in lung adenocarcinoma cells. Int J Oncol 43: 1569-1577, 2013.

12. Keaney J, Campbell M and Humphries P: From RNA interference technology to effective therapy: how far have we come and how far to go? Ther Deliv 2: 1395-1406, 2011.

13. Xia L, Guan W, Wang D, Zhang YS, Zeng LL, Li ZP, Wang G and Yang ZZ: Killing effect of Ad5/F35-APE1 siRNA recombinant adenovirus in combination with hematoporphrphyrin derivative-mediated photodynamic therapy on human nonsmall cell lung cancer. Biomed Res Int 2013: 957913, 2013.
14. Yi X, Zhao G, Zhang H, Guan D, Meng R, Zhang Y, Yang Q, Jia H, Dou K, Liu C, et al: MITF-siRNA formulation is a safe and effective therapy for human melasma. Mol Ther 19: 362-371, 2011

15. Hanker LC, Karn T, Mavrova-Risteska L, Ruckhäberle E, Gaetje R, Holtrich U, Kaufmann M, Rody A and Wiegratz I: SATB1 gene expression and breast cancer prognosis. Breast 20: 309-313, 2011

16. Selinger CI, Cooper WA, Al-Sohaily S, Mladenova DN, Pangon L, Kennedy CW, McCaughan BC, Stirzaker C and Kohonen-Corish MR: Loss of special AT-rich binding protein 1 expression is a marker of poor survival in lung cancer. J Thorac Oncol 6: 1179-1189, 2011.

17. Huang B, Zhou H, Wang X and Liu Z: Silencing SATB1 with siRNA inhibits the proliferation and invasion of small cell lung cancer cells. Cancer Cell Int 13: 8, 2013.

18. Bankert RB, Balu-Iyer SV, Odunsi K, Shultz LD, Kelleher RJ Jr, Barnas JL, Simpson-Abelson M, Parsons R and Yokota SJ: Humanized mouse model of ovarian cancer recapitulates patient solid tumor progression, ascites formation, and metastasis. PLoS One 6: e24420, 2011.

19. Fang XF, Hou ZB, Dai XZ, Chen C, Ge J, Shen H, Li XF, Yu LK and Yuan Y: Special AT-rich sequence-binding protein 1 promotes cell growth and metastasis in colorectal cancer. World J Gastroenterol 19: 2331-2339, 2013.

20. Cai S, Han HJ and Kohwi-Shigematsu T: Tissue-specific nuclear architecture and gene expression regulated by SATB1. Nat Genet 34: 42-51, 2003

21. Mir R, Pradhan SJ and Galande S: Chromatin organizer SATB1 as a novel molecular target for cancer therapy. Curr Drug Targets 13: 1603-1615, 2012. 